\title{
An inexpensive liquid dispenser
}

\author{
CHARLES W. HYATT \\ The Union Institute, Cincinnati, Ohio \\ and Yerkes Regional Primate Research Center \\ Emory University, Atlanta, Georgia \\ and \\ DAVID A. LEAVENS \\ University of Georgia, Athens, Georgia \\ and Yerkes Regional Primate Research Center \\ Emory University, Atlanta, Georgia
}

\begin{abstract}
An inexpensive liquid reinforcement dispenser was developed from a commercially available automobile windshield washer fluid pump. When tested on laboratory primates, this device proved to be as efficient and reliable as far more expensive models.
\end{abstract}

The dispensation of liquid reinforcements can be a valuable aid to behavioral scientists conducting research with laboratory animals. Yet the cost of commercially available liquid dispensers can be prohibitive. (The G5600 Series of Dipper Feeders from Gerbrands, Corp. starts at \$355.) In an effort to develop an automated system of liquid dispensation at a lower cost, a commercially available automobile windshield wiper fluid pump was adapted for the automatic dispensation of water and juice upon receipt of a signal from a minicomputer. This apparatus has provided successful delivery of liquid reinforcement as efficiently as far more expensive systems in repeated use with laboratory primates.

The need for the dispensation of nonsolid reinforcers has been recognized by many scientists performing research with laboratory animals. Heffner and Heffner (1982) describe a liquid reinforcement device developed in their study of hearing in elephants which used two solenoid-operated water valves; and, Thompson, Porter, O'Bryan, Heffner, and Heffner (1990) describe the development of a syringe-pump food-paste dispenser for under $\$ 350$ for use in hearing research with cats. These dispensers have proved appropriate for these experimenters because of relatively low cost and ease of construction; yet the cost of the second device is still significant, and

Portions of this research were supported by Grant NS-29574 to W. D. Hopkins and a grant from the National Center for Research Resources RR-00165 to the Yerkes Regional Primate Research Center. D.A.L. gratefully acknowledges the support of a Morris Doctoral Fellowship, Graduate School, Southern Illinois University, Carbondale, IL. Thanks to P. Bryan and A. Brodie for the figure illustration. The Yerkes Regional Primate Research Center is accredited by the American Association for Accreditation of Laboratory Animal Care. The APA standards for the ethical treatment of animals were adhered to during all aspects of this study. Correspondence should be addressed to C. W. Hyatt, Yerkes Regional Primate Research Center, Emory University, Atlanta, GA 30322 . both devices require some construction. The present authors sought to develop an even simpler and less expensive liquid dispenser apparatus that could be easily interfaced with microcomputers and automated systems, such as the testing software developed by Richardson, Washburn, Hopkins, Savage-Rumbaugh, and Rumbaugh (1990). This software package facilitates the responding by primates to computer-generated stimuli via the manipulation of a joystick. It then builds to more complex automated tasks such as options for maze running, discrimination learning set, and matching-to-sample tests, among others.

Five chimpanzees (Pan troglodytes), including 4 males and 1 female, between five and seven years of age, were trained on a modified version of matching-to-sample component of the Richardson et al. (1990) computer software package. In this task, the subject manipulated a joystick mounted onto its cage housing, in order to track the cursor first onto a sample stimulus on the monitor screen, and then onto either its match or a foil. An incorrect response was signaled by an unpleasant "buzz" sound, and a correct response was signaled by a pleasant "chime" sound, accompanied by a human-delivered squirt of fruit juice as reinforcement.

To automate the reinforcement procedure, a Roberk brand Auto Windshield Washer Pump was obtained from the Stant Corporation of Shelton, CT, through an auto parts store; the pump cost approximately $\$ 11$. This rotary motor pump was mounted to the plastic top of the computer housing unit, with Hose $1(1 / 8$ in. $\times 1 / 16$ in. latex $)$ going from a reservoir of juice (as much as 1 gallon) into the pump and Hose 2 going out from the pump to the cage mesh. (See Figure 1.) The receipt of a "correct" signal from the computer to a Keithley MetraByte DASCON-1 Relay Board mediated current from a $12-\mathrm{V}$ battery to the pump for $.5 \mathrm{sec}$, causing $2.5 \mathrm{cc}$ of juice to be dispensed. Liquid amounts dispensed could be varied with the time that the relay was left open, as programmed in the software. This 


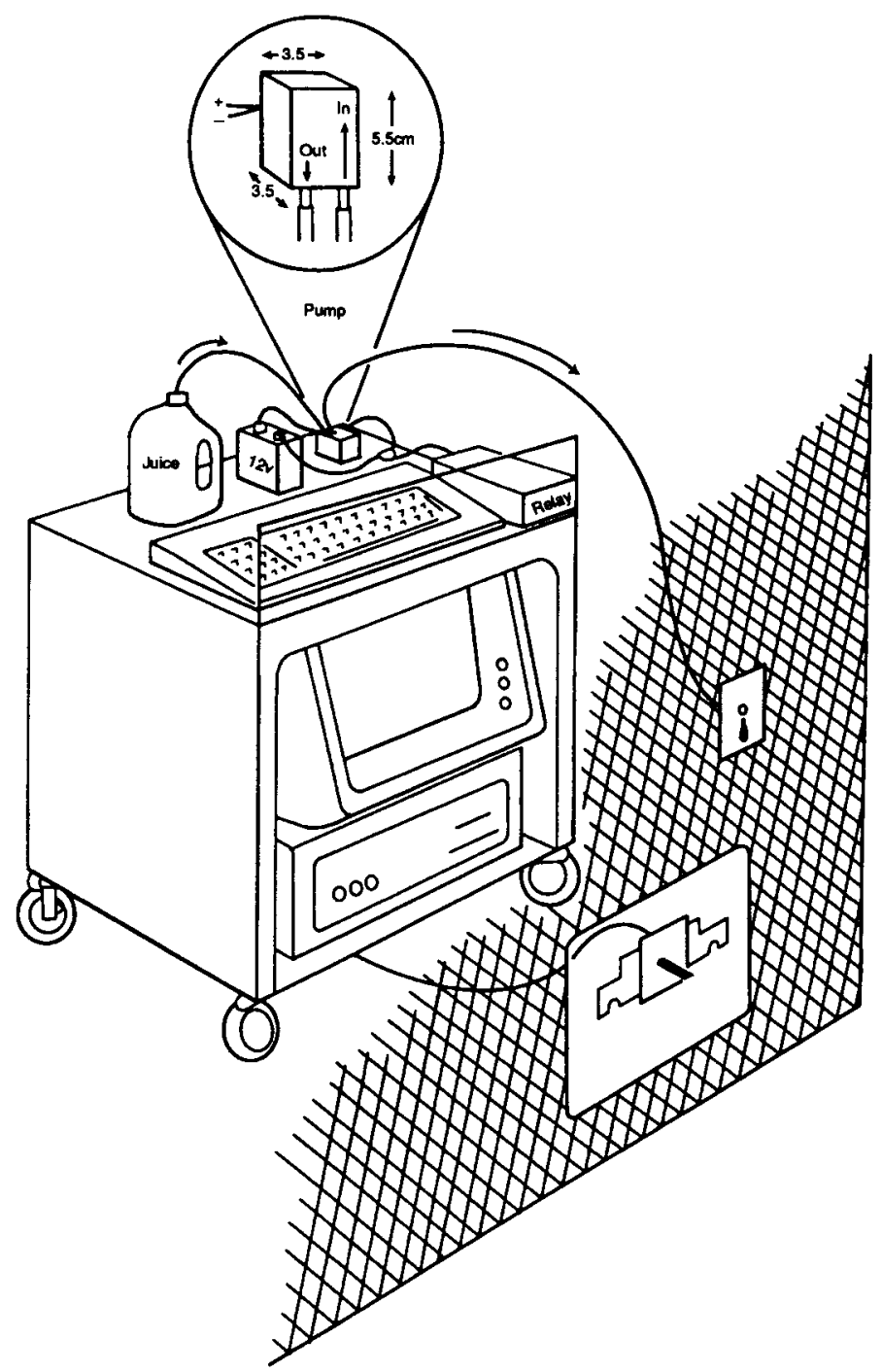

Figure 1. Pump, juice reservoir, hoses, battery, and relay board mounted on computer housing unit.

apparatus performed successfully in over 2,000 pretest trials and was then introduced to the 5 animal subjects for 25 (correct) trials per subject per day over 8 test days. No apparatus failures were noted over the 3,000 total pretest and test trails.

This liquid reinforcement dispenser device was inexpensive to obtain and simple to construct. Although premanufactured or solenoid-operated dispensers may interface with other equipment well, this apparatus was easily interfaced with the minicomputer, relay, and battery combination. In heavy use by laboratory primates it has demonstrated the potential to be as reliable and efficient as far more expensive models for a fraction of their costs.

\section{REFERENCES}

HefFner, R. S., \& HefFner, H. E. (1982). Hearing in the elephant: Absolute sensitivity, frequency discrimination, and sound localization. Journal of Comparative \& Physiological Psychology, 96, 926-944. Richardson, W. K., Washburn, D. A., Hopkins, W. D., SavageRumbaugh, E. S., \& Rumbaugh, D. M. (1990). The NASA/LRC Computerized Test System. Behavior Research Methods, Instruments, \& Computers, 22, 127-131.

Thompson, M., Porter, B., O'Bryan, J., Heffner, H. E., \& Heffner, R. S. (1990). A syringe-pump food-paste dispenser. Behavior Research Methods, Instruments, \& Computers, 22, 449-450.

(Manuscript received February 7,1995 ; revision accepted for publication January 22,1996 .) 